\section{THE SUPPRESSION OF REVERSE CURRENT IN X RAY COILS.}

By Reginald Morton, M.D. Tor., F.R.C.S. EdiN., PAST FRESIDENT, SECTION OF ELECTROTHERAPEUTICS, ROTAI SOCIETX OF MEDICLNE.

THE evils of inverse current are unpleasantly. familiar to all radiologists, and it is probable that the presence of this undesirable element is responsible for more spoilt plates, ruined tubes, and other disappointments than any other single cause. Curiously enough, there has been little or no effort made by the makers of $X$ ray coils and interrupters to diminish the amount of this rererse current, but rather the other way. Some ingenuity has been expended in the design of interrupters, but unfortunately in the wrong direction. The great idea seems to be to raise the rate of interruption to the highest possible limit, and they hare been helped in this by the high voltage of currentsupply that is rapidly becoming universal. The result is that in showrooms and exhibitions a coil working through a mercury "break" gives a dis. charge in air that is almost indistinguishable from that seen when an electrolytic interrapter is used. This is very impressive to those who do not know better, and, needless to say, the intending purchasel is not told that a large portion of the discharge is made up of reverse current, and, for $X$ ray purposes, worse than useless. $\mathrm{He}$ is made to understand that a valve tube must be used in circuit always, and accepts this as an essential part of the outfit. Incidentally a healthy demand is created for valve tubes; which doubtless is an advantage to the makers and dealers.

It would be out of place here to enlarge on the technical aspect of this question, and it is sufficient to say that recent developments of $\mathrm{X}$ ray plant, where they include a mercury interrupter, have been on quite wrong lines, and so far from helping this branch of investigation they have been a distinct hindrance. To get the best results in $X$ rays the current through the tabe must be uni-directional, and the voltage of the impulses must be as high as possible. The modern tendency is to increase the rererse current at the expense of the direct current we want; this is done in opposition to all electrical and magnetic principles, and is also opposed to efficiency in the work for which the apparatus is intended. Within the range of most of his work a mercury interrupter is the most useful one to the radiologist; it has its limitations, and when we trs to make it behare like one of the electrolytic variety we destroy many of its advantages, for which we gain nothing. If the intending purchaser of an X ray outfit of this kind will remember that there is only one test that is of any value-the amount of current the coil will pass through a normal tube with all the reverse current suppressed - and insist on a guarantee based solely on the uni-directional output, makers and dealers will soon be brought to their senses with adrantage to all concerned.

The trouble would not signify so very much if the usual device-the valve tube-were at all satisfactory. I hare tested and worked with every sort of valve tube I have been able to obtain, and I think ereryone who has had a large experience with them will bear me out when I say that it is doubtful if a more erratic and inefficient instru. ment exists. I admit that some have been less bad than most of the others. I hare not seen any that might be called really good, and at their poor best they introduce one more variable and uncertain factor in a problem that has too many already. That radiologists continue to use valve tubes proves no. more than that their apparatus is im. perfect and that the valve tube is the only methodi open to them for dealing with the reverse current.

To find a reliable method of suppressing this inverse current is a problem that has interested me for some time, and while what seems to be the best method occurred to me some years ago, for various. reasons it has not been developed until quite recently. It is applicable to any form of mercury break in which the contacts are directly connected to the shaft of the motor, or to the jets if there are fixed contact blades, as in the ordinary jet break: it is not easily applicable to breaks of the "Sanax" type as at present constructed. It has the great advantages that there is nothing to wear out, and consequently nothing to renew; the conditions are constant at all times, and no appreciable resistance. is added to the circuit during the passage of the current at "break." The inverse current-the. current at " make"-is completely suppressed.

The scheme is shown in the accompanying: diagram. In the centre the general arrangement
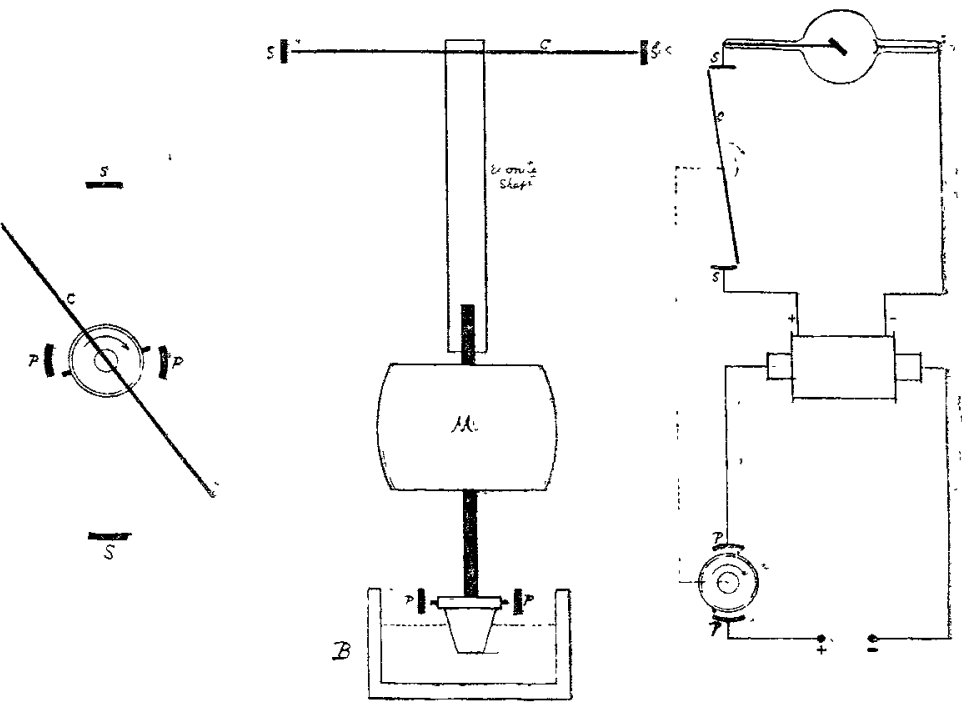

is shown in elevation. The break $\mathrm{B}$ is driven by the motor $M$, and to the upper prolongation of the spindle of the latter is attached an ebonite shaft which carries the wire'connector $\mathrm{c}$ which just clears the two segments s placed in one side of the secondary circuit. The break in the primary circuit and the connector in the secondary circuit thus rotate together, and aro effectually insulated from each other by the ebonite shaft. It is also evident that the connector and break can be so. adjusted to each other that the secondary circuit remains open except at the moment of "break" the only time it need be closed. Turning to the. left of the diagram we see the jets: (rotating clock. wise) just about to impinge on the primary contact $P, P$, and the secondary circuit is open at the two gaps between the ends of $a$ and the seg. ments s, s. In practice the total gap is from 6 to 8 inches, which is too much for the secondary current at "make" to get across. This reverse current dies out before the conneator $\mathrm{c}$ gets near to the segments $s, s$, and the $X$ ray tube remains unaffected by it. The connexions. in the primary and secondary circuits are shown on the right of the diagram, and if it is borne in mind that the centres joined by the dotted line represent the rotating parts in both. 
circuits, the relative position of the essential parts at the moment of "break" will be easily understood. Below the jets are just leaving the primary contacts P P, and above the connector $\mathrm{C}$ is coming into line with the segments $s$ s, allowing the secondary current to flow through the tube with practically no resistance. The scheme may be described, in other words, as a combined interrupter for the primary and secondary circuits, so set that as one circuit is closed the other is open.

The simplicity and efficiency of the device will be apparent to anyone acquainted with $X$ ray apparatus, and the wonder is that it has not been put into use before. The scheme is similar in principle to the mica valve of Mr. Leslie Miller, but in this case the wide air-gap is preferable as a resistance to the mica disc, and it admits of more complete closure of the circuit at the moment of "break." My device has been patented for the benefit of Messrs. Newton and Wright, who have borne all the trouble and expense of developing the idea in practical form. ${ }^{1}$

The apparatus is mounted in a closed cabinet with the coil on top and the break and its attachments inside. Needless to say, any coil can be fitted by merely adapting the supports upon which it rests. The controls for the break are placed on one end of the cabinet, and a switch table of the simplest form attached by a flexible cable regulates the output of the coil. I believe the apparatus is one that will become popular among radiologists for such work as comes within the range of a coil and mercury break. It adds very little to the original cost of the $\mathrm{X}$ ray outfit, and this is very soon compensated for in the elimination of expense for valve tubes, and the longer life and steadier working of the $\mathrm{X}$ ray tubes. The greatest advantage is that results are more uniformly good in every way.

\section{ROYAL COLLEGE OF SURGEONS OF ENGLAND.}

MeEting of CounciL.

AN ordinary meeting of the Council was held on March 12th, Sir RICKMaN GODLEE, the President, being in the chair.

A letter was read from Mr. Jonathan Hutchinson resigning his seat on the Council on account of pressure of hospital work.

The President stated that the vacancy thus occasioned would be filled at the annual meeting of Fellows in July.

A report was read from Mr. C. H. Golding-Bird on the proceedings of the Central Midwives Board during the past year. The best thanks of the Council were given to $\mathrm{Mr}$. Golding-Bird for his services as the representative of the College on that Board, and he was re-elected for another year.

Sir Henry Morris was re-elected for one year as the representative of the College on the General Medical Council.

A letter was read from Mr. D'Arcy Power reporting his attendance before the Royal Commission on Venereal Diseases to give evidence as requested by the Council.

$$
\text { Fixity of Tenure of Medical Officers of Health. }
$$

The PREsIDENT stated that in accordance with the wish of the Council expressed at their last meeting he and the Vice-Presidents had received at the College some medical officers of bealth and had conferred with them on the subject of fixity of tenure. It was resolved to send the following letter to the President of the Local Government Board :-

"The attention of the Council of the Royal College of Surgeons has been directed to the desire of the medical

1 The apparatus is being demonstrated this evening (Friday, March 20th) at the Flectrotherapeutic Section of the Royal Society of Medicine. officers of health under the Local Government Board to secure fixty of tenure and some definite system of super. annuation and pensions, and they have been asked to support the endeavour which is now being made to bring this matter under the consideration of His Majesty's Government.

The Council are aware that this is no new question, and that it may be considered from more than one point of view. They have endeavoured to make themselves acquainted with the arguments put forward on both sides, and the facts as far as they have been able to ascertain them.

Though feeling a special interest in the diplomates of the College, the Council recognise that if the request cannot be supported on public groundis it is not worthy of consideration. It is to this point of view, therefore, that they have exclu. sively directed their attention.

It appears to the Council that there must be something wrong with a system under which the guardians of the public health hold appointments terminable at short notice under those whose interests are likely to be interfered with by the exposure of unsanitary conditions, or the suggestion of sanitary improvement. Yet this is what the present system in many districts involves. The Council have been impressed by the confession of men occupying important positions, that they are conscious of being influenced in the discharge of their duties by the fear of losing their appointments.

Moreover, it is often stated that the medical profession is becoming more and more alive to the unattractiveness of public health appointments, even those commanding good salaries where the tenure is insecure and there is no system of superannuation. It appears likely, therefore, that the quality of the applicants for them will deteriorate.

Considering the vital importance of the matter at stake the Council, whilst fully recognising the weight of the arguments adduced against the proposed change, which they have endeavoured to consider impartially, cannot think that they are strong enough to outweigh those in favour of the request of the medical officers of health.

The Council, therefore, feel that it would be for the advantage of the community if security of tenure with a corresponding system of superannuation were granted to medical officers of health under the Local Government Board and they venture to express the hope that it may be possible for His Majesty's Ministers to give favourable consideration to the representations which are now being made to them on these questions."

The diploma of Member was conferred upon the following two gentlemen who have passed the requisite examinations and have now complied with the by-laws of the College: John Harold Cascaden, M.D. Toronto, Toronto University and London Hospital ; and Thomas Trench Thompson, M.B., B.S. New Zealand, Otago University.

\section{ROYAL COMMISSION ON VENEREAL DISEASES.}

AT the twenty-second meeting of the Royal Commission on Venereal Diseases evidence was given by $\mathrm{Mr}$. D'Arcy Power, surgeon and lecturer on surgery at St. Bartholomew's Hospital, and one of the representatives before the Commission of the Royal College of Surgeons and the Royal Society of Medicine.

Mr. D'Arcy Power said that from the surgeon's point of view he looked upon gonorrhoea as the more serious disease for the individual and syphilis for the race. In general surgery the effects of gonorrhcea were far-reaching, and it was an error to teach that it was a local and curable disease. Syphilis seemed to $\mathrm{Mr}$. Power to be even more dangerous to the State than to the individual. The expectation of life was materially shortened for a person who had been infected with syphilis ; the immediate danger extended to the second generation, and the vitality of the stock seemed diminished for several generations. Syphilis gave surgery a large amount of work. It predisposed, Mr. Power thought, to cancer and tubercle. The particular danger of the disease lay in the fact that the subsequent effects bore no necessary relation to the severity of the initial lesions.

Mr. Power thought that a diminution in the incidence of syphilis would best be brought about by better in struction of the medical student, and that each general 